\section{Summary}

By use of a skin-sensitivity test, evidence of infection with toxocariasis has been found in $7(2.1 \%)$ of 329 apparently healthy persons, in $26(13.6 \%)$ of 191 persons who had had poliomyelitis, and in $26(7.5 \%)$ of 349 sufferers from epilepsy.

It has been confirmed that the reservoir of infection among dogs and cats in the London area is considerable, $21.3 \%$ of dogs and $21 \%$ of cats having been found to have ova of $T$. canis and $T$. cati respectively in their faeces.

It is postulated, and evidence is given to support the view, that larvae of $T$. canis and $T$. cati in their migration from the lumen of the alimentary tract to the blood and tissues, may carry with them bacteria, viruses, and other infective agents, and that in this way some patients have been infected with poliomyelitis.

The larvae do not usually mature in man, but, after wandering in the tissues, die, and a focus of granulomatous tissue reaction forms around their disintegrating bodies. When larvae reach the brain, as they have been shown to do, this process may cause epilepsy. The toxocaral skin test has been found to be positive four times more frequently in epileptic persons than in healthy controls.

It is apparent from this and earlier works that dogs and cats may constitute a considerable public-health hazard.
This study was made possible by a grant from the Medical Research Council, to whom we express our thanks. We are grateful to Lord Brain for helpful suggestions, for his interest in the work, and for suggesting Lingfield as a centre for the investigations on epilepsy, and to Dr. W. W. Gooddy for facilities in the Department of Neurology, University College Hospital. We also thank Sir Herbert Seddon for his help in gaining access to patients who had had poliomyelitis and to the London County Council for some similar facilities. We acknowledge much valuable technical assistance by Mr. A. I. Shah, and are grateful for the grant from the Hospital for Tropical Diseases Research Fund, which made it possible to employ him.

\section{REFERENCES}

Beautyman, W., and Woolf, A. L. (1951). 7. Path. Bact., 63, 635. Beaver, P. C. (1962). Bull. Soc. Path. exot., 55, 555.

Bisseru, B., Woodruff, A. W., and Hutchinson, R. I. (1966). Brit. med. F., $1,1583$.

Brain, Lord, and Allan, B. (1964). Lancet, 1, 1355.

Chaudhuri, R. N., and Saha, T. K. (1959). Ibid., 2, 493.

Chaudhuri, R. N., and Saha, T. K. (1959). Ibid., 2,

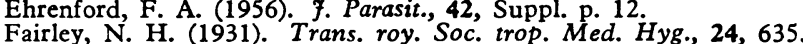

Fairley, N. H. (1931). Trans. roy. Soc. trop. Med. Hy
Hutchison, W. M. (1965). Nature (Lond.), 206, 961.

Maplestone, P. A., and Bhaduri, N. V. (1940). Indian f. med. Res., 28, 595.

Mochizuki, H., Tomimura, T., and Oka, T. (1954). F. infect. Dis., 95, 260.

Ridley, D. S., and Hawgooa, B. C. (1956). F. clin. Path., 9, 74.

Sprent, J. F. A. (1955). Parasitology, 45, 31.

Wilson, S., and Thompson, A. E. (1964), F. Path. Bact., 87, 169.

Woodruff, A. W., and Thacker, C. K. (1964). Brit. med. f., 1, 1001.

\title{
Spontaneous Cerebrospinal-fluid Rhinorrhoea
}

\author{
A. M. NUSSEY,* M.D., F.R.C.P.
}

Brit. med. F., 1966, 1, 1579-1580

Escape of cerebrospinal fluid through the nose is quite common in head injuries, either immediately or after some delay. It may follow nasal or cranial operations, spring from infections of paranasal sinuses or from prolonged pressure on the base of the skull by tumours or hydrocephalus, and sometimes it can be traced to congenital anomalies such as nasal meningocele or meningo-encephalocele.

The diagnosis of spontaneous cerebrospinal-fluid rhinorrhoea is acceptable only when the frequent and less common causes listed above do not apply. Some authors (Coleman and Troland, 1947) would deny the title to cases where an obvious cause, such as a bony defect in the region of the cribriform plate, is found, but such exclusiveness is hardly justified, and even on less rigid criteria the condition is still very much of a collector's piece.

One of the earliest reviews of cerebrospinal-fluid rhinorrhoea was made by St. Clair Thomson in a beautifully written monograph in 1899, but Coleman and Troland (1947), who wrote a classical paper on the subject, were prepared to accept only St. Clair Thomson's personal case and 12 others culled from the literature as fulfilling their criteria of spontaneous cerebrospinalfluid rhinorrhoea. There seems little doubt now that several other cases, such as that of Aubin et al. (1944) in which a minor gap was found in the cribriform plate, which Coleman and Troland rejected, should be included in the series. Coleman and Troland (1947) reported incidentally three further examples, and subsequently reasonably documented single instances have been added by Cloward and Cunningham (1947), Kleinfeld et al. (1950), Kahn (1951), Oldberg (1954), Berryman (1955), Sen Gupta (1956), Troland (1960), Bracewell and Carter (1963), Riser et al. (1964), and three double records by Love and Gay (1947), Rand (1953), and O'Connell (1964) O'Connell (1964) estimated the total number of cases of spontaneous cerebrospinal-fluid rhinorrhoea as less than 75 , and this figure would appear to make a generous allowance for some inaccessible and more doubtful publications.

The ages of the patients have ranged from 25 to 59 , and females have shown a striking preponderance over males in a ratio of about $10: 1$. The feature common to all cases has been the almost constant drip, about as often from one side of the nose as the other, of clear watery material which on analysis could be shown to be cerebrospinal fluid. Position of the head usually influenced the flow, forward flexion particularly making it greater, and, as might be expected, pressure on the jugular veins increased the escape. The quantity of fluid lost has been estimated by a few observers, the average in 24 hours being around 1 pint ( 0.6 litre), but accurate measurement is difficult, especially as the cerebrospinal fluid often drops back into the pharynx and may even find its way into the lungs.

The onset in most cases has been quite abrupt, sometimes after a respiratory infection, but generally for no obvious reason. The condition attracted attention mostly because of the nuisance it gave rise to, but in a few patients single or repeated meningitis, which according to the published accounts (Cloward and Cunningham, 1947 ; Kleinfeld, 1950 ; Troland, 1960) has not been particularly severe, has been an important feature. Besides the drip from the nose some patients have complained, for the reason already mentioned, of a salty taste in the throat, and of an irritating cough.

The duration of the cerebrospinal-fluid rhinorrhoea has varied from weeks to years. The flow ceased at times spontaneously, or after meningitis, or intranasal manipulations such as the instilling of silver nitrate drops, but the therapeutic value of the latter cannot be accepted, because patients treated in this 
way and those who received no treatment at all appeared equally liable to relapses after remissions of varying duration. The only. sure way of stopping the flow, and incidentally preventing an ascending infection, has been by opening the skull on the appropriate side, and inserting a piece of muscle, fascia, or gel foam over the affected part of the dura through which the leak took place. Such a procedure is perfectly safe in competent neurosurgical hands, though it usually results in the loss of whatever sense of smell existed on the affected side before the operation. E.N.T. surgeons have endeavoured to stop. the flow of cerebrospinal fluid by operating via the nose, but though some successes have been claimed (Vrabec and Hallberg, 1964) the method has the obvious drawback of being a virtually blind approach.

\section{Case Report}

A woman, now aged 61, who had had a mild attack of poliomyelitis in infancy but no other serious illnesses or injury in the past, was first admitted as an emergency with meningitis early in 1957. She was mentally confused and her cerebrospinal fluid was found to contain 13,300 white blood cells (mostly polymorphs)/cmm., 340 mg. $/ 100 \mathrm{ml}$. of protein, and less than $10 \mathrm{mg} . / 100 \mathrm{ml}$. of sugar. The polymorphs in the cerebrospinal fluid were seen to enclose degenerative Gram-positive diplococci, but culture of the fluid was sterile. The patient made a rapid recovery on systemic and intrathecal penicillin and on adjuvant treatment with chloramphenicol (Chloromycetin) and sulphadiazine.

She subsequently remained well, but at the end of July 1964 she was referred to the out-patient department because of a drip of clear fluid from the right nostril, which had been going on for two months. She was afraid that this manifestation might lead to a recurrence of meningitis, because, and this was something we learned for the first time, she had had a similar discharge intermittently for 12 months before her attack in 1957. Her fears proved to be justified, because about five weeks later she had to be readmitted with headache, vomiting, and drowsiness. She showed signs of meningeal irritation, and lumbar puncture yielded turbid fluid containing 6,900 polymorphs/cmm., protein $255 \mathrm{mg} . / 100 \mathrm{ml}$., and sugar $21 \mathrm{mg} . / 100 \mathrm{ml}$. This time organisms were neither seen on direct inspection nor cultured. She again recovered quickly on systemic and intrathecal penicillin and oral sulphadimidine, but, unlike the first time, the right-sided nasal drip continued after this infection, the patient waking in the morning with her pillow soaked. The fluid issuing from the nose contained $5 / \mathrm{c} . \mathrm{mm}$. red blood cells, $34 \mathrm{mg} . / 100 \mathrm{ml}$. of protein, $703 \mathrm{mg} . / 100 \mathrm{ml}$ of chloride, and 54 mg./100 ml. of sugar. It was clear that she was suffering from so-called spontaneous cerebrospinal-fluid rhinorrhoea, the cause of which led to her two attacks of meningitis, and she was referred to the Midland Centre for Neurosurgery and Neurology. There it was demonstrated that iophendylate (Myodil) injected into the lumbar theca found its way after a few days into paranasal air sinuses. Subsequently the anterior cranial fossa was explored through a right frontal craniotomy. The right olfactory tract was found to be adherent to the base of the skull in front of the sphenoidal ridge, and at this point there was a small defect through which a probe could be passed into the sphenoidal air sinus. The defect was packed with a piece of fascia and this was followed by an uneventful recovery apart from the fact that now her slight residual sense of smell is confined to the left side. She has remained well to date.

\section{Discussion}

The frequent inability-particularly in earlier records-to pinpoint the route taken by the escaping cerebrospinal fluid in patients with spontaneous rhinorrhoea has encouraged much speculation on the subject. Thus it has been variously suggested that the cerebrospinal fluid reaches the nose through a remnant of the craniopharyngeal canal (Loftus, 1923 ; Johnston, 1926), through a fistula in a retained embryonic lumen of the olfactory bulb (Britt, 1935), or through holes in the cribriform plate missed out by nerve fibres (Berryman, 1955). The explanation which accords best with the evidence is that dysplasia of meninges related to the olfactory nerves makes a leak of cerebro- spinal fluid possible (Rand, 1963) and that bony defects in the region of the cribriform plate which facilitate such an extension of arachnoid render their possessors particularly liable to have spontaneous cerebrospinal-fluid rhinorrhoea (Adson 1941; Aubin et al., 1944). O'Connell (1964) thought that the normal rhythmic variations in the pressure of cerebrospinal fluid which he observed previously (1953) could pave the way to a leak when an anatomical variation exposed the frail cribriform plate to the full effect of this tidal movement, and this could account for the late age-incidence. It seems likely that diligent search would reveal a cause in every case of spontaneous cerebrospinalfluid rhinorrhoea and that the prefix "primary" some authors have adopted for this condition is no longer justified. Even this still leaves open the question of why the rhinorrhoea actually starts, unless one accepts the idea (Juaregg, 1936) that sneezing, or another act which increases intracranial pressure suddenly, forces open a pathway which hitherto was only a potential one.

All kinds of materials, and particularly indigo carmine, have been injected into the lumbar subarachnoid space to confirm the nature and side of the nasal loss. In the example here recorded Myodil was employed, but such procedures are not without danger and in most cases ordinary observations should suffice to establish the diagnosis. A few authors failed to mention the side of the nose from which the cerebrospinal fluid escaped, but for the rest the laterality was not in doubt. Rarely, cases of spontaneous cerebrospinal-fluid rhinorrhoea, such as the one published by Rockett et al. (1964), in which the leak was eventually traced to an opening from the pontine cistern into the middle ear, may remain unexplained for a long time despite most searching investigations. The condition is probably more common than the scanty literature would lead one to expect, and would perhaps be diagnosed oftener if it were borne in mind more frequently.

\section{Summary}

A case of spontaneous cerbrospinal-fluid rhinorrhoea which was complicated by two attacks of meningitis is recorded and the literature on the subject briefly reviewed.

It is suggested that when an adult, particularly a female, suffers from prolonged discharge of clear fluid from one side of the nose the possibility of spontaneous cerebrospinal-fluid rhinorrhoea should be considered, especially if such a patient also gives a history of meningitis.

I would like to thank Mr. J. G. Hamilton, of the Midland Centre for Neurosurgery and Neurology, for operating on this patient.

\section{REFERENCES}

Adson, A. W. (1941). Ann. Surg., 114, 697.

Aubin, A., Martin, R., Klein, H., and Sureau (1944). Ann. Oto-laryng. (Paris), 62, 147.

Berryman, G. H. (1955). F. Allergy, 26, 71.

Bracewell, A and Carter, R. L. (1963). F. Laryng., 77, 777.

Bracewell, A., and Carter, R. L. (1935). F. nerv. ment. Dis., 81, 654 .

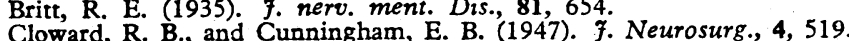

Cloward, R. B., and Cunningham, E. B. (1947) f. Neurosurg., 4, 519.

Coleman, C. C., and Troland, C. E. (1947). A

Johnston, W. H. (1926). Ann. Otol. (S. Louis), 35, 1205.

Kahn, A. (1951). 9. Amer. med. Ass., 146, 728.

Kleinfeld, M., Axelrod, M., and Cohen, A. (1950). N.Y. St. F. Med., 50 ,

Loftus, J. E. (1923). F. Amer. med. Ass., 80, 841.

Love, J. G., and Gay, J. R. (1947). Arch. Otolaryng., 46, 40.

O'Connell, J. E. A. (1953). Brain, 76, 279.

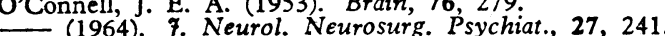

Oldberg, E. (1954). Postgrad. Med., 16, 1.

Rand, R. W. (1953). Bull. Los Angeles neurol. Soc., 18, 74.

Riser, M., Lazorthes, G., and Anduze-Acher, H. (1964). Rev. Oto-neuroophthal., 36, 103 .

Rockett, F. X., Wittenborg, M. H., Shillito, J., and Matson, D. D (1964). Amer. ₹. Roentgenol., 91, 640.

Sen Gupta, S. K. (1956). F. Laryng., 70, 428.

Thomson, St. Clair (1899). The Cerebro-spinal Fluid; Its Spontaneons Escape From the Nose. Cassel, London.

Escape From the Nose. Cassel, London.
Troland, C. E. (1960). Arch. Otolaryng., 72, 254.

Vrabec, D. P., and Hallberg, O. E. (1964). Arch. Otolaryng., 80, 218.

Wessels, A. (1939). Ann. Otol. (St. Louis), 48, 528. 